\title{
Increased EZH2 expression during the adenoma-carcinoma sequence in colorectal cancer
}

\author{
MAYUKO OHUCHI $^{1}$, YASUO SAKAMOTO ${ }^{1}$, RYUMA TOKUNAGA ${ }^{1}$, YUKI KIYOZUMI $^{1}$, KENICHI NAKAMURA $^{1}$, \\ DAISUKE IZUMI ${ }^{1}$, KEISUKE KOSUMI $^{1}$, KAZUTO HARADA ${ }^{1}$, JUNJI KURASHIGE ${ }^{1}$, MASAAKI IWATSUKI ${ }^{1}$, \\ YOSHIFUMI BABA ${ }^{1}$, YUJI MIYAMOTO ${ }^{1}$, NAOYA YOSHIDA ${ }^{1}$, TAKASHI SHONO ${ }^{2}$, \\ HIDEAKI NAOE $^{2}$, YUTAKA SASAKI ${ }^{2}$ and HIDEO BABA ${ }^{1}$
}

Departments of ${ }^{1}$ Gastroenterological Surgery, and ${ }^{2}$ Gastroenterology and Hepatology, Graduate School of Medical Sciences, Kumamoto University, Kumamoto 860-8556, Japan

Received December 13, 2016; Accepted May 11, 2017

DOI: $10.3892 / \mathrm{ol} .2018 .9240$

\begin{abstract}
The adenoma-carcinoma sequence, the sequential mutation and deletion of various genes by which colorectal cancer progresses, is a well-established and accepted concept of colorectal cancer carcinogenesis. Proteins of the polycomb repressive complex 2 (PRC2) function as transcriptional repressors by trimethylating histone $\mathrm{H} 3$ at lysine 27; the activity of this complex is essential for cell proliferation and differentiation. The histone methyltransferase enhancer of zeste homolog 2 (EZH2), an essential component of $\mathrm{PRC} 2$, is associated with the transcriptional repression of tumor suppressor genes. EZH2 expression has previously been reported to increase with the progression of pancreatic intraductal papillary mucinous neoplasm. Thus, we hypothesized that EZH2 expression also increases during the adenoma-carcinoma sequence of colorectal cancer. The present study investigated changes in EZH2 expression during the colorectal adenoma-carcinoma sequence. A total of 47 patients with colorectal adenoma, 20 patients with carcinoma in adenoma and 43 patients with colorectal carcinoma who underwent surgical or endoscopic resection were enrolled in this study. Non-cancerous tissue from the clinical specimens was also examined. The association between EZH2 expression, pathology and expression of tumor suppressor genes during colorectal carcinogenesis were analyzed. Each specimen was immunohistochemically stained for EZH2, proliferation marker protein $\mathrm{Ki}-67$ (Ki-67), cyclin-dependent kinase inhibitor (CDKN) 1A (p21), CDKN1B (p27) and CDKN2A (p16). Total RNA was extracted
\end{abstract}

Correspondence to: Dr Hideo Baba, Department of Gastroenterological Surgery, Graduate School of Medical Sciences, Kumamoto University, 1-1-1 Honjo Road, Chuo, Kumamoto 860-8556, Japan

E-mail: hdobaba@kumamoto-u.ac.jp

Key words: enhancer of zeste homolog 2, p21, colorectal cancer, adenoma-carcinoma sequence from formalin-fixed paraffin-embedded blocks and reverse transcription-quantitative polymerase chain reaction analysis of these genes was performed. Ki-67 and EZH2 expression scores increased significantly during the progression of normal mucosa to adenoma and carcinoma $(\mathrm{P}=0.009)$, and EZH2 expression score was positively associated with Ki-67 expression score $(\mathrm{P}=0.02)$. Conversely, p21 mRNA and protein expression decreased significantly, whereas expression of p27 and p16 did not change significantly. During the carcinogenesis sequence from normal mucosa to adenoma and carcinoma, EZH2 expression increased and p21 expression decreased significantly. EZH2 may therefore contribute to the development of colorectal cancer from adenoma via suppression of $\mathrm{p} 21$.

\section{Introduction}

Colorectal cancer (CRC) is the third most common type of cancer and the fourth most common cause of cancer-associated mortality worldwide (1). In recent years, the overall effects of the environment, lifestyle factors (2), and inherited and acquired genetic/epigenetic alterations (3-5) on CRC, and the interactions between them have been clarified. Dysplastic adenomas are the most common form of premalignant precursor lesions (6). Fearon and Vogelstein (7) first suggested the concept of the adenoma-carcinoma sequence as a genetic model for colorectal tumorigenesis; they proposed that colorectal carcinoma develops from adenoma through a series of genetic events, including genetic mutation and the loss of tumor suppressor genes. However, the epigenetic mechanism of tumorigenesis in colorectal carcinoma remains unclear.

Polycomb group proteins are global repressors of gene expression that bring about transcriptional suppression epigenetically through the formation of polycomb repressor complexes (PRCs), including PRC1 and PRC2 $(8,9)$. Enhancer of zeste homolog 2 (EZH2) is a catalytic subunit of PRC2 (10-13). In addition to EZH2, PRC2 contains the non-catalytic subunits embryonic ectoderm development and suppressor of zeste 12. EZH2 serves as a histone lysine methyltransferase that mediates the trimethylation of 
lysine 27 of histone $\mathrm{H} 3$ ( $\mathrm{H} 3 \mathrm{~K} 27$ ) to silence expression of PRC2-target genes involved in lineage differentiation $(14,15)$. EZH2 is overexpressed in several types of cancer and its expression is associated with aggressiveness and poor prognosis in breast, prostate and ovarian cancer, and cholangiocarcinoma (16-21). Previously, EZH2 was reported to be associated with accelerated cell proliferation and malignant progression in pancreatic intraductal papillary mucinous neoplasm and pancreatic cancer via the gene silencing of cyclin-dependent kinase inhibitor (CDKN) 1B (p27) expression (22), and in melanoma and pancreatic cancer via repression of CDKN1A (p21) $(23,24)$. However, the role of EZH2 in the progression of colorectal cancer has not yet been investigated. Thus, the purpose of the present study was to examine the role of alterations in EZH2 expression in colorectal cancer progression.

\section{Patients and methods}

Patients. Between April 2009 and March 2013, 209 patients with colorectal adenoma or carcinoma in adenoma (CIA) were treated endoscopically in the Department of Gastroenterology and Hepatology, Graduate School of Medical Sciences, Kumamoto University (Kumamoto, Japan), and 33 patients with colorectal adenoma and 18 patients with CIA underwent surgical resection at the Department of Gastroenterological Surgery, Graduate School of Medical Sciences, Kumamoto University. Between April 2013 and March 2014, 43 patients with early colorectal carcinoma underwent surgical resection at the Department of Gastroenterological Surgery, Graduate School of Medical Sciences, Kumamoto University. Only the patients who provided written informed consent for the use of their resected tissues for the current study were enrolled. A total of 110 patients were enrolled in the current study, including 70 with adenoma lesions, 22 with CIA lesions, and 43 with carcinoma lesions. Certain patients had more than two adenoma lesions. A total of 42 lesions were resected endoscopically and 68 lesions were resected surgically. The clinicopathological features of the 110 patients are summarized in Table I. The average age was 67.7 years (range, 34-88), 62 patients were male and 48 patients were female.

The present study protocol was approved by the institutional review board of Kumamoto University Hospital. The study was conducted in compliance with the Declaration of Helsinki and all patients provided written informed consent for the use of their resected tissues for clinical study.

Immunohistochemical (IHC) staining. IHC staining was performed on $4 \mu \mathrm{m}$ sections obtained from formalin-fixed (at $36^{\circ} \mathrm{C}, 10 \%$ formalin, $48 \mathrm{~h}$ ) paraffin-embedded blocks. Sections were pretreated through autoclaving $\left(15 \mathrm{~min}\right.$, at $\left.121^{\circ} \mathrm{C}\right)$ in Histofine antigen retrieval solution ( $\mathrm{pH}$ 9.0) (Nichirei Biosciences, Inc., Tokyo, Japan) for EZH2 and proliferation marker protein $\mathrm{Ki}-67$ (Ki-67) IHC, or through microwaving for $20 \mathrm{~min}$ in Histofine antigen retrieval ( $\mathrm{pH}$ 9.0) for CDKN2A (p16), p21, and p27. Endogenous peroxidase activity was blocked for $5 \mathrm{~min}$ at room temperature using 3\% hydrogen peroxidase, and the sections were incubated with diluted antibodies overnight at $4^{\circ} \mathrm{C}$. EnVision ${ }^{+}$solution (Dako; Agilent
Technologies, Inc., Santa Clara, CA, USA) was then applied for $30 \mathrm{~min}$ at room temperature. The reaction products were visualized with a diaminobenzidine solution followed by counterstaining with Mayer's hematoxylin for $5 \mathrm{~min}$ at room temperature. The following primary antibodies were used: Mouse monoclonal antibody (mAb) against EZH2 (1:50 dilution; cat. no. 612666; BD Biosciences, San Jose, CA, USA); mouse mAb against Ki-67 (1:100 dilution; cat. no. M7240; Dako; Agilent Technologies, Inc.), rabbit polyclonal Ab against p16 (1:50 dilution; cat. no. 4824; CST Biological Reagents Company Limited, Shanghai, China), rabbit mAb against p21 (1:50 dilution; cat. no. sc-397; Santa Cruz Biotechnology, Dallas, TX, USA); and mouse mAb against p27 (1:150 dilution; cat. no. 610241; BD Biosciences, San Jose, CA, USA). The following secondary antibodies were used: anti-mouse IgG goat antibody (cat. no. K4001; Dako; Agilent Technologies, Inc.) for EZH2, Ki-67 and p27 and anti-rabbit IgG goat antibody (cat. no. K4003; Dako; Agilent Technologies, Inc.) for p16 and $\mathrm{p} 21$, applied for $30 \mathrm{~min}$ at room temperature. Chromogenic reaction was visualized with a diaminobenzidine solution (cat. no. 349-00903; Wako Pure Chemical Industries, Ltd., Osaka, Japan). Positive controls for immunostaining were performed using pancreatic intraductal papillary mucinous neoplasm tissue and negative controls were prepared by omission of the primary antibody. We evaluated IHC staining using OLYMPUS DP27 microscope (confocal type laser scan) and we examined 5 fields (magnification, x100) using DP2-BSW (ver. 2.1, Olympus Life Science). IHC analysis was conducted using a dual scoring system of staining intensity and staining extent. The staining intensity was defined as 0,1 or 2 , denoting negative, weak, or strong staining, respectively. The staining extent was defined as the percentage of cancer cells that were positively stained. IHC score was calculated as the product of the staining intensity and staining extent by 2 researchers, M.O. and Y.S.

Reverse transcription-quantitative polymerase chain reaction $(R T-q P C R)$. Total RNA was successfully extracted from 32 selected lesions (4 normal lesions, 12 adenomas, 9 CIA lesions and 7 carcinomas). Formalin-fixed paraffin-embedded blocks were sectioned into 3-5 serial $10-\mu \mathrm{m}$ slices. Randomly selected lesions were macrodissected by comparison with hematoxylin and eosin staining (5 $\mathrm{min}$ at room temperature). Total RNA was extracted using an RNeasy FFPE kit (Qiagen Sciences, Inc., Gaithersburg, MD, USA) according to the manufacturer's protocol and converted to cDNA by reverse transcription using Oligo(dT) $)_{12-18}$ primer (cat. no. 18418-012), random primer (cat. no. 48190-011), $10 \mathrm{mM}$ dNTP mix (cat. no. 18427-088), SuperScript ${ }^{\mathrm{TM}} \mathrm{III}$ Reverse Transcriptase (cat. no. 18080-085) and RNaseOUT ${ }^{\mathrm{TM}}$ Recombinant Ribonuclease Inhibitor (cat. no. 10777-019; all purchased from Invitrogen; Thermo Fisher Scientific, Inc., Waltham, MA, USA). Random Hexamers Annealing was performed for $5 \mathrm{~min}$ at $25^{\circ} \mathrm{C}$, cDNA synthesis for $60 \mathrm{~min}$ at $50^{\circ} \mathrm{C}$ and termination reaction for $15 \mathrm{~min}$ at $70^{\circ} \mathrm{C}$. To determine the mRNA expression levels of EZH2, p27, p21 and p16, a qPCR assay was performed using a LightCycler 480 system (Roche Applied Diagnostics, Basel, Switzerland) under the following reaction conditions: Initial denaturation at $95^{\circ} \mathrm{C}$ for $10 \mathrm{~min}, 10 \mathrm{sec}$ at $95^{\circ} \mathrm{C}, 30 \mathrm{sec}$ at $60^{\circ} \mathrm{C}, 1 \mathrm{sec}$ at $72^{\circ} \mathrm{C}$ and $10 \mathrm{sec}$ at $40^{\circ} \mathrm{C}$ using LightCycler 480 
Table I. Clinicopathological characteristics of patients.

Tissue type

\begin{tabular}{|c|c|c|c|c|}
\hline \multirow[b]{2}{*}{ Variable } & & \multirow[b]{2}{*}{ P-value } \\
\hline & Adenoma $(n=47)$ & Carcinoma in adenoma $(\mathrm{n}=20)$ & Carcinoma $(\mathrm{n}=43)$ & \\
\hline Sex & & & & 0.23 \\
\hline Male & 22 & 14 & 26 & \\
\hline Female & 25 & 6 & 17 & \\
\hline Age, years ${ }^{a}$ & $69 \pm 9.57$ & $66 \pm 18.4$ & $71.5 \pm 13.7$ & 0.44 \\
\hline Location & & & & 0.77 \\
\hline $\mathrm{C} / \mathrm{A} / \mathrm{T} / \mathrm{D} / \mathrm{S} / \mathrm{R}^{\mathrm{b}}$ & $8 / 12 / 4 / 5 / 8 / 10$ & $2 / 4 / 2 / 1 / 5 / 6$ & $3 / 6 / 6 / 5 / 9 / 14$ & \\
\hline \multicolumn{5}{|l|}{ Tumor depth } \\
\hline Tis/T1 & - & - & $23 / 20$ & \\
\hline Tumor diameter, $\mathrm{mm}^{\mathrm{a}}$ & $27.5 \pm 22.5$ & $29 \pm 23.1$ & $46 \pm 25.9$ & 0.51 \\
\hline
\end{tabular}

Table II. Primer sequences for polymerase chain reaction analysis.

Primer

\begin{tabular}{llc}
\cline { 2 - 3 } Gene & \multicolumn{1}{c}{ Forward } & Reverse \\
\hline EZH2 & GACTGGCGAAGAGCTGTTTT & TVTTTVGATGCCGACATACTT \\
p21 & GGCAGACCAGCATGACAGATT & GCGGATTAGGGCTTCCTCTT \\
p16 & TCGTGCTGATGCTACTGAGG & ATCTATGCGGGCATGGTTAC \\
p2 & GAGGTGGAGAGGGGCAGC & TTCGGGGAACCGTCTGAAAC
\end{tabular}

EZH2, enhancer of zeste homolog 2; p16, cyclin-dependent kinase inhibitor 2A; p21, cyclin-dependent kinase inhibitor 1A; p27, cyclin-dependent kinase inhibitor $1 \mathrm{~B}$.

Probe Master (cat. no. 04-887-301-001, Roche Life Science, Basel, Switzerland) and the $2^{-\Delta \Delta C q}$ method was used (25). Probes and primers were designed using the Roche probe library system (Table II). $\beta$-actin was used as a reference.

Statistical analysis. All statistical analysis was performed using JMP ${ }^{\circledR} 10.0$ software (SAS Institute Inc., Cary, NC, USA). $\mathrm{P}<0.05$ was considered to indicate a statistically significant difference. Data are presented as the mean \pm standard deviation and analysis was performed 5 times per experiment. In comparison of clinicopathological variables between tissue types, $\chi^{2}$ test and Fisher's exact test were used. In comparison of EZH2, Ki-67, p21 expression score, unpaired Student's t-test was used. In evaluation of association between EZH2, Ki-67 and p21, Pearson's product-moment correlation coefficient was used. Following univariate analysis, variables with a $\mathrm{P}<0.05$ were selected for multivariate analysis.

\section{Results}

EZH2 expression increases with increased cell proliferative activity. Carcinoma and adenoma cells are often present in the same lesion (Fig. 1); this is regarded as theoretical proof of the adenoma-carcinoma sequence.
First, IHC staining and RT-qPCR were performed for $\mathrm{EZH} 2 . \mathrm{EZH} 2$ expression was detected in the nuclei of colorectal adenomas, CIA lesions and colorectal adenocarcinomas (Fig. 2A). IHC staining was used to analyze EZH2 expression. The IHC score increased parallel to pathological changes among normal tissue, adenoma and carcinoma. The expression of EZH2 was significantly higher in colorectal adenomas compared with that of normal lesions $(\mathrm{P}<0.0001)$, and also higher in CIA lesions compared with colorectal adenomas $(\mathrm{P}=0.0006)$; however, no significant association was identified in EZH2 expression between CIA and colorectal carcinomas (Fig. 2B).

Ki-67 expression associates with EZH2 expression. Proliferative activity was assessed using Ki-67 immunostaining. Ki-67 expression was also observed in the nuclei of all tissue types (Fig. 3A). The IHC score of Ki-67 gradually increased along with the pathological change from normal tissue to adenoma and carcinoma. The expression of Ki-67 was significantly higher in colorectal adenomas compared with that of normal lesions $(\mathrm{P}=0.01$; Fig. 3B). Although no significant association was identified in Ki-67 expression between colorectal adenomas and CIA lesions, expression was significantly higher in colorectal carcinomas compared with adenoma lesions $(\mathrm{P}=0.0009$; Fig. 3B). There was a significant 


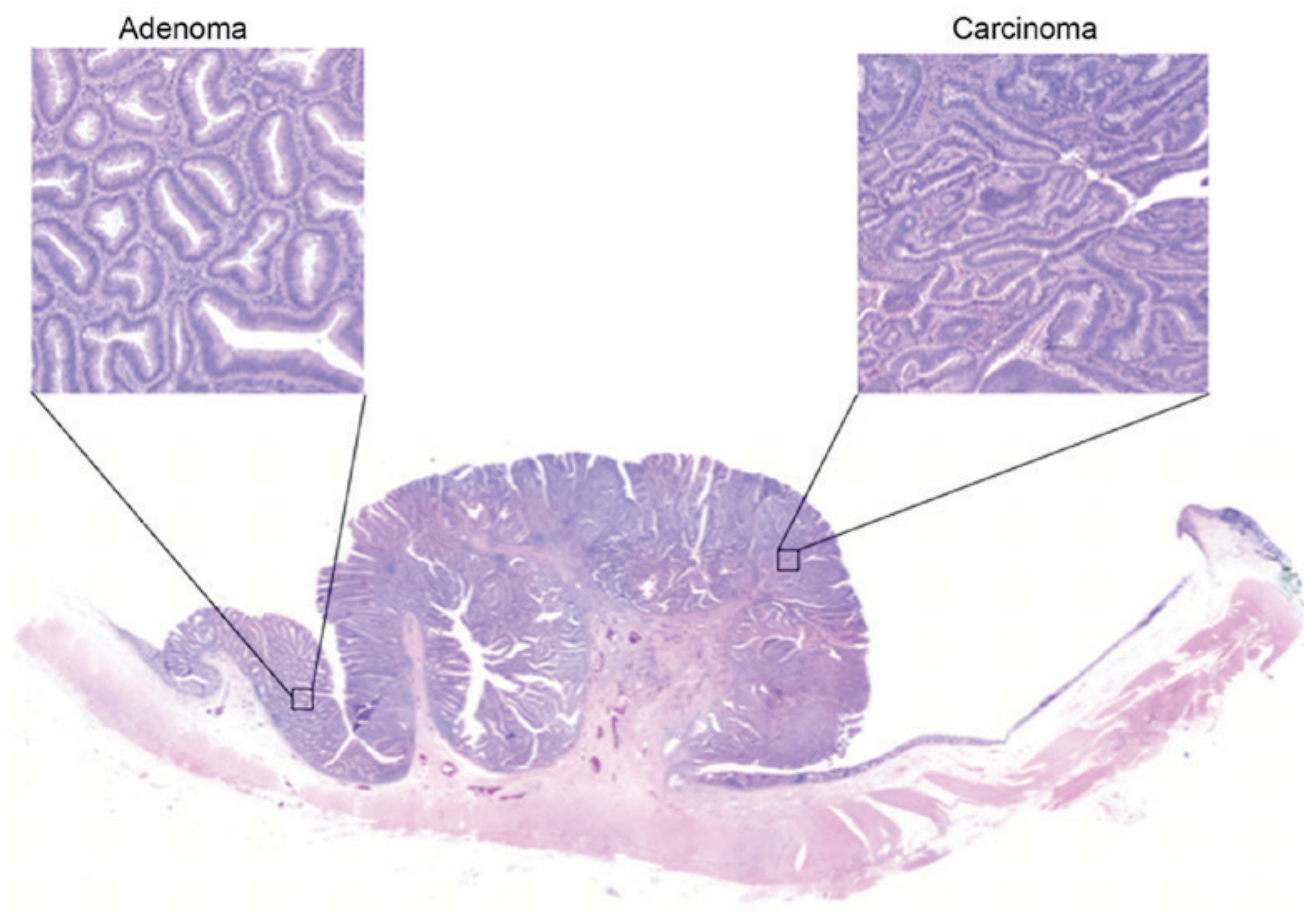

Figure 1. Hematoxylin and eosin staining of colorectal adenoma and carcinoma (magnification, x100). As presented, carcinoma is often mixed with adenoma in the same lesion.

A Normal

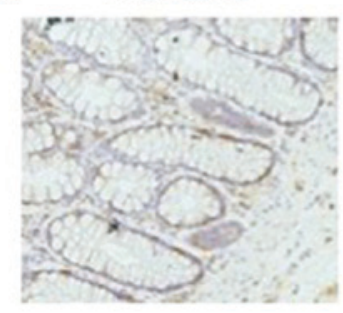

Adenoma

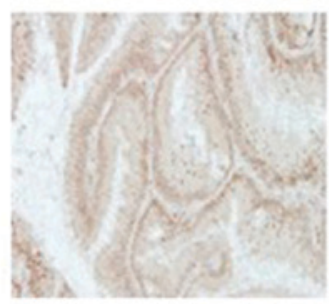

CIA

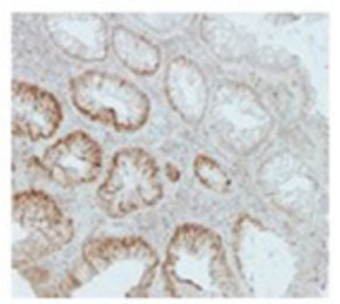

\section{Carcinoma}

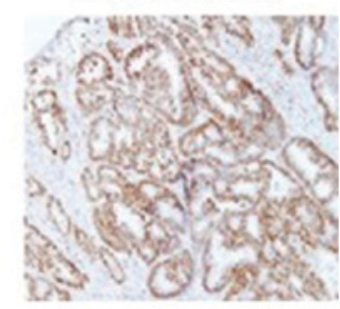

B

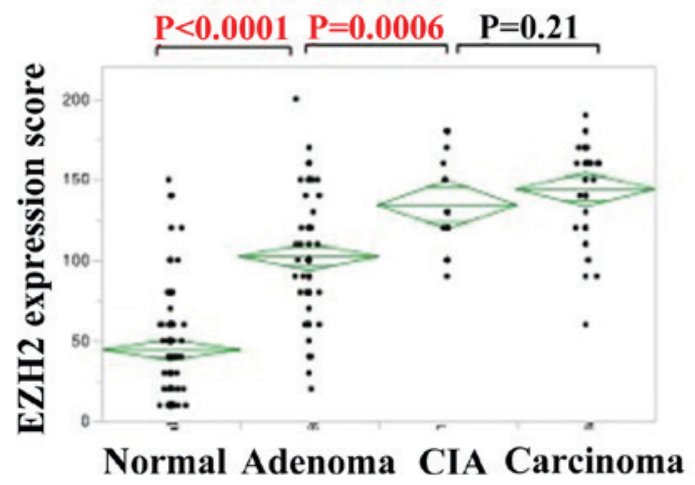

Figure 2. EZH2 expression increases as colorectal cancer progresses. (A) Immunohistochemical staining of EZH2 in the indicated tissues, suggesting colorectal cancer progression (magnification, x100). (B) IHC score of EZH2 in the progression of colorectal cancer. The staining intensity was defined as 0 , 1 or 2, denoting negative, weak, or strong staining, respectively. IHC score was calculated as the product of the staining intensity and staining extent. EZH2, enhancer of zeste homolog 2; CIA, carcinoma in adenoma.

positive association identified between EZH2 and Ki-67 expression ( $\mathrm{P}=0.02$; Fig. $3 \mathrm{C}$ ). Therefore, the proliferative activity of the cell increased during the disease progression of colorectal adenocarcinomas, particularly during the change from normal to adenoma, and it is likely that EZH2 serves a notable role in the adenoma-carcinoma sequence of colorectal adenocarcinoma.

Tumor suppressor p21 is downregulated with the progression of colorectal carcinomas. EZH2 has been reported to promote 
A

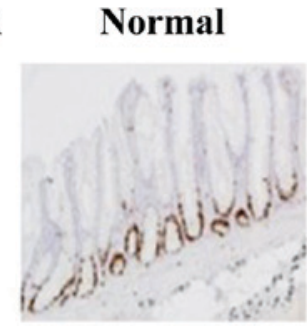

Adenoma

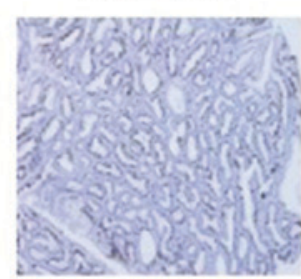

CIA

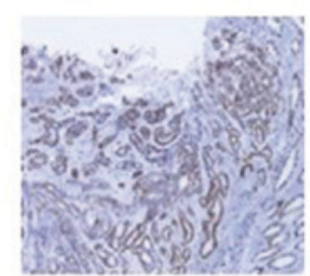

Carcinoma

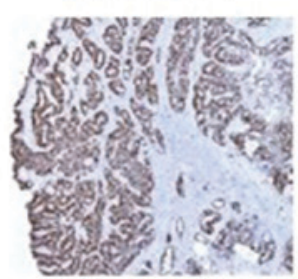

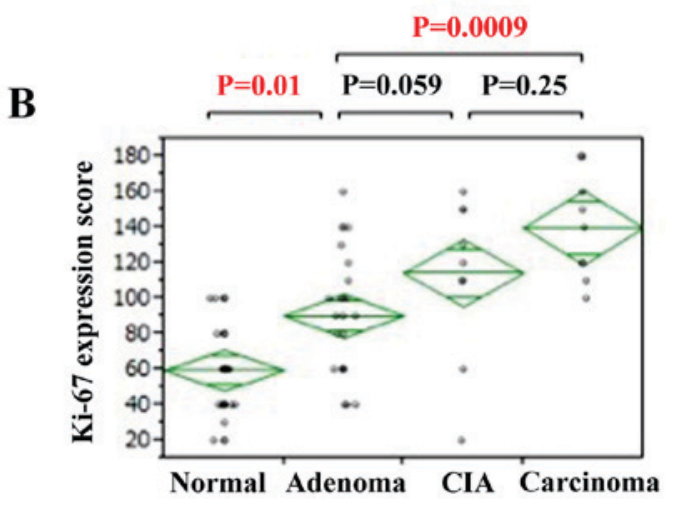

C

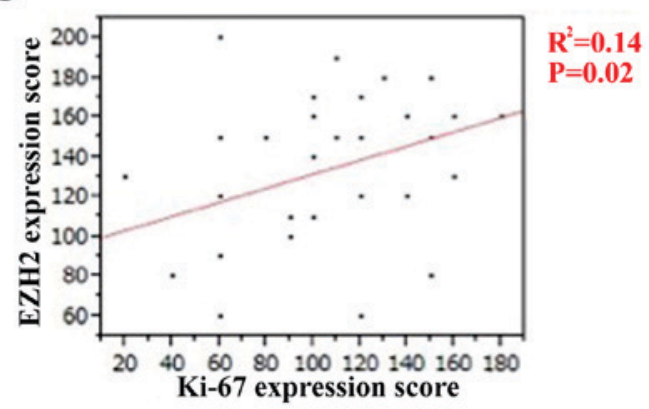

Figure 3. Increased cell proliferation activity during colorectal cancer progression. (A) Immunohistochemistry of Ki-67 at the indicated degree of colorectal cancer progression (magnification, x100). (B) IHC score of Ki-67 in the progression of colorectal cancer. The staining intensity was defined as 0,1 or 2 , denoting negative, weak, or strong staining, respectively. IHC score was calculated as the product of the staining intensity and staining extent. (C) The association between EZH2 and Ki-67 expression. The $\mathrm{R}^{2}$ value was obtained using Pearson's product-moment correlation coefficient. CIA, carcinoma in adenoma; EZH2, enhancer of zeste homolog 2; Ki-67, proliferation marker protein Ki-67.

A

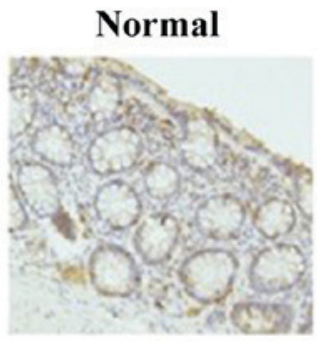

Adenoma

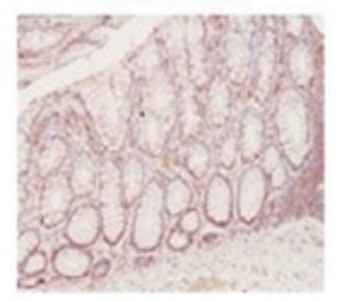

CIA

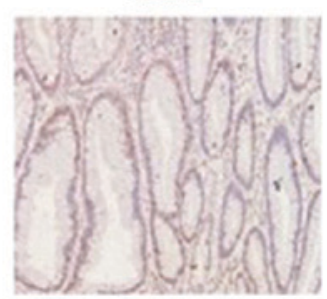

Carcinoma

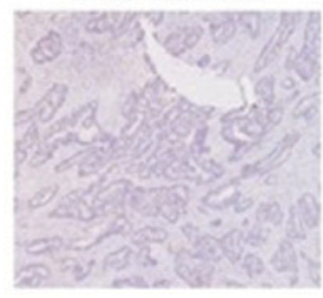

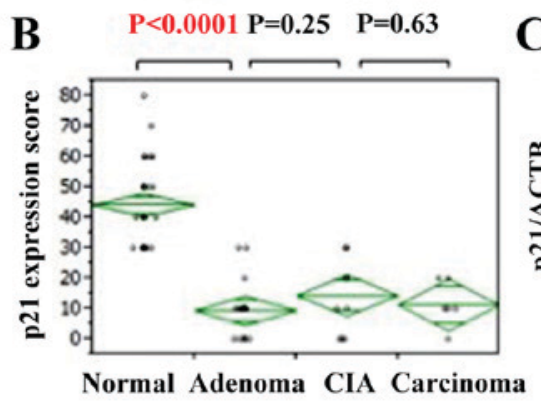

C

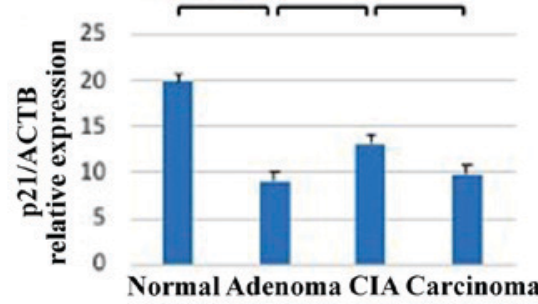

D

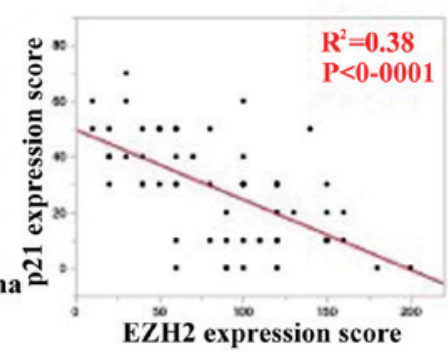

Figure 4. p21 expression is decreased in the progression of colorectal cancer. (A) Immunohistochemistry of p21 in various lesions of colorectal cancer progression (magnification, $\mathrm{x} 100$ ). (B) p21 protein expression scores in the progression of colorectal cancer. (C) p21 expression in the progression of colorectal cancer at the mRNA level. (D) The association between $\mathrm{p} 21$ and EZH2 expression. The $\mathrm{R}^{2}$ value was obtained using Pearson's product-moment correlation coefficient. CIA, carcinoma in adenoma; EZH2, enhancer of zeste homolog 2; p21, cyclin-dependent kinase inhibitor 1A.

cellular proliferation via downregulation of tumor suppressor proteins, including $\mathrm{p} 27, \mathrm{p} 21$, and $\mathrm{p} 16$ (22-25). To assess the mechanism of this accelerated cell proliferation during the adenoma-carcinoma sequence of colorectal cancer, IHC staining and qPCR analyses of p27, p21, and p16 expression were performed (Fig. 4). Whereas p21 exhibited strong nuclear localization in normal tissue, its expression was downregulated in adenomas, CIA lesions and carcinomas (Fig. 4A). The IHC score was significantly lower in adenomas compared with that of normal tissue (Fig. 4B). Similarly, p21 expression at the mRNA 
level tended to be significantly lower in adenomas, CIA lesions, and carcinomas compared with in normal lesions (Fig. 4C). EZH2 and p21 expression was identified to be significantly inversely associated (Fig. 4D). However, the expression of p27 and p16 did not change significantly during the progression of colorectal carcinoma (data not shown). Thus, the downregulation of p21 appears to be an important factor in accelerated cell proliferation during colorectal cancer progression.

Next, as p21 is a well-known transcriptional target of p53 (26), p53 expression was assessed via IHC staining. Although the IHC score of p53 significantly increased with the pathological change from normal to adenoma and carcinoma, no significant association was identified between p21, and p53 expression (data not shown).

\section{Discussion}

The present study demonstrated that increased EZH2 expression was associated with the progression of colorectal cancer; concomitantly, expression of the tumor suppressor protein p21 was decreased.

Tumorigenesis is a multi-step process associated with genetic and epigenetic alterations. In 1990, Fearon et al and Vogelstein et al reviewed the genetic model for colorectal tumorigenesis $(7,27)$. Allelic losses of chromosome 5q, which is associated with the gene for familial adenomatous polyposis, have been observed in $\sim 30 \%$ of colorectal adenomas in patients without polyposis $(28,29)$, suggesting that this allelic loss is an early event in colorectal tumor progression. In addition, Vogelstein et al (27) revealed that mutations in RAS were observed in intermediate and late adenoma, whereas allelic loss of chromosome 17p, which was associated with the TP53 gene, was observed in late adenoma carcinoma. These allelic losses induce other alterations, including tumor suppressor gene hypomethylation (7), which has also been identified to occur early in colorectal tumorigenesis; in one study, $\sim 1 / 3$ of the DNA regions had lost methyl groups, even in extremely small adenomas (27). Thus, genetic and epigenetic alterations occur in the early stage of colorectal tumorigenesis. In the present study, EZH2 expression was increased in adenomas, suggesting that EZH2 expression is an early event in colorectal tumorigenesis. This finding suggests that EZH2 overexpression may be involved in epigenetic alterations that occur early in the progression from normal epithelial cells to adenoma.

In the present study, of the tumor suppressor proteins $\mathrm{p} 27$, p21 and p16, only p21 was expressed at higher levels in normal tissue than in cancerous tissue; its expression was inversely associated with EZH2 expression and no significant association was identified between p21 expression and p53 expression. Moreover, expression of EZH2 correlated with the expression of Ki-67. p21 is a mediator of p53 tumor suppressor activity and inhibits cell-cycle progression by inhibiting the activity of cyclin-dependent kinase-cyclin complexes and proliferating cell nuclear antigen (30). It has been reported that $\mathrm{p} 21$ is stimulated by multiple pathways that are independent of p53 (30). The findings of the present study suggest that EZH2-mediated acceleration of cell proliferation via downregulation of p21 may serve an essential role in the progression of normal cells to adenoma, and that $\mathrm{p} 21$ is regulated not by $\mathrm{p} 53$ but by EZH2 in the progression of colorectal cancer. A reduction in the expression of $\mathrm{p} 21$ has been associated with the progression of colorectal cancer $(31,32)$. Bukholm and Mesland (31) reported an association between reduced/absent p21 expression, and the development of metastases and mortality owing to cancer disease. Furthermore, Pasz-Walczak et al (32) reported an inverse correlation between p21 expression and clinical stage. In addition, Hubaux et al (33) revealed that inhibiting EZH2 using short hairpin RNA increased p21 protein levels in small cell lung cancer (33) and pancreatic ductal adenocarcinoma (34). It was proposed that the mechanism underlying the regulation of p21 expression by EZH2 may involve downregulation of runt-related transcription factor 3 (RUNX3), a transactivator of p21, by EZH2 via trimethylation of H3K27 in the promoter region (35). Chi et al (36) revealed that RUNX3 suppresses cell growth by inducing p21 expression in gastric cancer. However, Kodach et al (37) reported that knockdown of EZH2 did not result in RUNX3 re-expression in colorectal cancer cell lines. The authors demonstrated that the downregulation of RUNX3 was associated with RUNX3 DNA methylation and that knockdown of EZH2 prevented the re-silencing of RUNX3 following the removal of demethylating agents (37). Thus, further studies are required to clarify the association between EZH2 and p21 expression.

A notable limitation of the present study is the small number of samples due to the single-institutional study design. In particular, CIA samples were relatively rare compared with adenomas or carcinomas. Further studies including a larger number of samples are therefore required. In conclusion, the results of the present study suggest that EZH2 upregulation serves an important role in the progression of colorectal cancer via p21 downregulation.

\section{Acknowledgements}

Not applicable.

\section{Funding}

No funding was received.

\section{Availability of data and materials}

All data generated or analyzed during this study are included in this published article.

\section{Authors' contributions}

YSak, YM and HB designed and directed the project. MO performed the experiments and collected all the clinicopathological data. YSak, RT, YK, KN, DI, KK, KH, JK, MI, YB and NY supported the experiments. TS, HN and YSas assisted with the collection of clinicopathological data. MO wrote the paper and YSak, YM and HB revised the manuscript and agreed that this study was appropriately investigated and to be accountable for all aspects of the study. All authors read and approved the final manuscript.

\section{Ethics approval and consent to participate}

The present study protocol was approved by the institutional review board of Kumamoto University Hospital. All patients 
provided written informed consent for the use of their resected tissues for clinical study.

\section{Patient consent for publication}

Patients provided their consent for the publication of this data.

\section{Competing interests}

The authors declare that they have no competing interests.

\section{References}

1. Brenner H, Kloor M and Pox CP: Colorectal cancer. Lancet 383 : 1490-1502, 2014

2. Khandekar MJ, Cohen P and Bruce M: Molecular mechanisms of cancer development in obesity. Nat Rev Cancer 11: 886-895, 2011.

3. Fearon ER: Molecular genetics of colorectal cancer. Annu Rev Pathol 6: 479-507, 2011

4. Saif MW and Chu E: Biology of colorectal cancer. Cancer J 16: 196-201, 2010.

5. Issa JP: Colon cancer: It's CIN or CIMP. Clin Cancer Res 14: 5939-5940, 2008.

6. Jass JR: Classification of colorectal cancer based on correlation of clinical, morphological and molecular features. Histopathology 50: 113-130, 2007.

7. Fearon ER and Vogelstein B: A genetic model for colorectal tumorigenesis. Cell 61: 759-767, 1990.

8. Alkema MJ, Bronk M, Verhoeven E, Otte A, van't Veer LJ, Berns A and van Lohuizen M: Identification of Bmil-interacting proteins as constituents of a multimeric mammalian polycomb complex. Gene Dev 11:226-240, 1997.

9. Kuzmichev A, Nishioka K, Erdjument-Bronmage, Tempst P and Reinberg D: Histone methyltransferase activity associated with a human multiprotein complex containing the Enhancer of Zeste protein. Gene Dev 16: 2893-2905, 2002.

10. Ketel CS, Andersen EF, Vargas ML, Suh J, Strome S and Simon JA: Subunit contributions to histone methyltransferase activities of fly and worm polycomb group complexes. Mol Cell Biol 25: 6857-6868, 2005.

11. Schwartz YB, Kahn TG, Nix DA, Li XY, Bourgon R, Biggin M and Pirrotta V: Genome-wide analysis of Polycomb targets in Drosophila melanogaster. Nat Genet 38: 700-705, 2006.

12. Schuettengruber B, Ganapathi M, Leblanc B, Portoso M, Jaschek R, Tolhuis B, van Lohuizen M, Tanay A and Cavalli G: Functional anatomy of polycomb and trithorax chromatin landscapes in Drosophila embryos. PLoS Biol 7: e13, 2009.

13. Boyer LA, Piath K, Zeitlinger J, Brambrink T, Medeiros LA, Lee TI, Levine SS, Wernig M, Tajonar A, Ray MK, et al: Polycomb complexes repress developmental regulators in murine embryonic stem cells. Nature 441: 349-353, 2006.

14. Cao R and Zhang Y: The functions of E(Z)/EZH2-mediated methylation of lysine 27 in histone H3. Curr Opin Genet Dev 14: 155-164, 2004

15. Simon JA and Lange CA: Roles of the EZH2 histone methyltransferase in cancer epigenetics. Mutat Res 647: 21-29, 2008.

16. Kleer CG, Cao Q, Varambally S, Shen R, Ota I, Tomlins SA, Ghosh D, Sewalt RG, Otte AP, Hayes DF, et al: EZH2 is a marker of aggressive breast cancer and promotes neoplastic transformation of breast epithelial cells. Proc Natl Acad Sci USA 100: 11606-11611, 2003.

17. Bachmann IM, Halvorsen OJ, Collett K, Stefansson IM, Straume O, Haukaas SA, Salvesen HB, Otte AP and Akslen LA: EZH2 expression is associated with high proliferation rate and aggressive tumor subgroups in cutaneous melanoma and cancers of the endometrium, prostate, and breast. J Clin Oncol 24 268-273, 2006.

18. Varambally S, Dhanasekaran SM, Ahou M, Barrette TR, Kumar-Sinha C, Sanda MG, Ghosh D, Pienta KJ, Sewalt RG, Otte AP, et al: The polycomb group protein EZH2 is involved in progression of prostate cancer. Nature 419: 624-629, 2002.

19. Saramäki OR, Tammela TL, Martilkainen PM, Vessella RL and Visakorpi T: The gene for polycomb group protein enhancer of zeste homolog 2 (EZH2) is amplified in late-stage prostate cancer. Gene Chromosome Canc 45: 639-645, 2006.
20. Li H, Cai Q, Godwin AK and Zhang R: Enhancer of zeste homolog 2 promotes the proliferation and invasion of epithelial ovarian cancer cells. Mol Cancer Res 8: 1610-1618, 2010.

21. Nakagawa S, Okabe H, Sakamoto Y, Hayashi H, Hashimoto D, Yokoyama N, Sakamoto K, Kuroki H, Mima K, Nitta H, et al: Enhancer of zeste homolog 2 (EZH2) promotes progression of cholangiocarcinoma cells by regulating cell cycle and apoptosis. Ann Surg Oncol 20 (Suppl 3): S667-S675, 2013.

22. Kuroki H, Hayashi H, Okabe H, Hashimoto D, Takamori H, Nakahara O, Nakagawa S, Fukushima Y, Chikamoto A, Beppu T, et al: EZH2 is associated with malignant behavior in pancreatic IPMN via p27Kip1 downregulation. PLoS One 9: e100904, 2014

23. Fan T, Jiang S, Chung N, Alikhan A, Ni C, Lee CC and Hornyak TJ: EZH2-dependent suppression of a cellular senescence phenotype in melanoma cells by inhibition of p21/CDKN1A expression. Mol Cancer Res 9: 418-29, 2011.

24. Ougolkov AV, Billim V and Billadeau DD: Regulation of pancreatic tumor cell proliferation and chemoresistance by the histone methyltransferase enhancer of zeste homologue 2. Clin Cancer Res 14: 6790-6796, 2008.

25. Livak KJ and Schmittgen TD: Analysis of relative gene expression data using real-time quantitative PCR and the 2(-Delta Delta C(T)) method. Methods 25: 402-408, 2001.

26. Abbas T and Dutta A: p21 in cancer, intricate networks and multiple activities. Nat Rev Cancer 9: 400-414, 2009.

27. Vogelstein B, Fearon ER, Hamilton SR, Kern SE, Preisinger AC, Leppert M, Nakamura Y, White R, Smits AM and Bos JL: Genetic alterations during colorectal-tumor development. N Eng J Med 319: 525-532, 1988 .

28. Sasaki M, Okamoto M, Sato C, Sugio K, Soejima J, Iwama T, Ikeuchi T, Tonomura A, Miyaki M and Sasazuki T: Loss of constitutional heterozygosity in colorectal tumors from patients with familial polyposis coli and those with nonpolyposis colorectal carcinoma. Cancer Res 49: 4402-4406, 1989.

29. Goelz SE, Vogelstein B, Jamilton SR and Feinberg AP: Hypomethylation of DNA from benign and malignant human colon neoplasms. Science 228: 187-190, 1985.

30. Abbas T and Dutta A: p21 in cancer: Intricate networks and multiple activities. Nat Rev Cancer 9: 400-414, 2009.

31. Bukholm IK and Mesland JM: Protein expression of p53, p21 (WAF1/CIP1), bcl-2, Bax, cyclin D1 and pRb in human colon carcinomas. Virchows Arch 436: 224-228, 2000.

32. Pasz-Walczak G, Kordek R and Faflik M: P21 (WAF1) expression in colorectal cancer: Correlation sith P53 and cyclin D1 expression, clinicopathological parameters and prognosis. Pathol Res Pract 197: 683-689, 2001.

33. Hubaux R, Thu KL, Coe BP, MacAulay C, Lam S and Lam WL: EZH2 promotes E2F-driven SCLC tumorigenesis through modulation of apoptosis and cell-cycle regulation. J Thorac Oncol 8: 1102-1106, 2013.

34. Batchu RB, Qazi AM, Gruzdyn OV, Semaan A, Seward SM, Chamala S, Dhulipala VB, Bouwman DL, Weaver DW and Gruber SA: EZH2-shRNA-mediated upregulation of p21waf1/cip1 and its transcriptional enhancers with concomitant downmodulation of mutant p53 in pancreatic ductal adenocaricinoma. Surgery 154: 739-747, 2013.

35. Yoo KH and Hennighausen L: EZH2 methyltransferase and H3K27 methylation in breast cancer. Int J Biol Sci 8: 59-65, 2012.

36. Chi XZ, Yang JO, Lee KY, Ito K, Sakakura C, Li QL, Kim HR, Cha EJ, Lee YH, Kaneda A, et al: RUNX3 suppresses gastric epithelial cell growth by inducing p21(WAF1/Cip1) expression in cooperation with transforming growth factor $\{$ beta\}-activated SMAD. Mol Cell Biol 25: 8097-8107, 2005.

37. Kodach LL, Jacobe RJ, Heijmans J, van Noesel CJ, Langers AM, Verspaget HW, Hommes DW, Offerhaus GJ, van den Brink GR and Hardwick JC: The role of EZH2 and DNA methylation in the silencing of the tumour suppressor RUNX3 in colorectal cancer. Carcinogenesis 31: 1567-1575, 2010. 